\title{
Characterization of plasma chemistry and ion energy in cathodic arc plasma from Ti-Si cathodes of different compositions
}

Anders Eriksson, I. Zhirkov, Martin Dahlqvist, Jens Jensen, Lars Hultman and J. Rosen

\section{Linköping University Post Print}

\section{Tweet}

N.B.: When citing this work, cite the original article.

Original Publication:

Anders Eriksson, I. Zhirkov, Martin Dahlqvist, Jens Jensen, Lars Hultman and J. Rosen, Characterization of plasma chemistry and ion energy in cathodic arc plasma from Ti-Si cathodes of different compositions, 2013, Journal of Applied Physics, (113).

http://dx.doi.org/10.1063/1.4802433

Licencee: American Institute of Physics (AIP)

http://www.aip.org/

Postprint available at: Linköping University Electronic Press

http://urn.kb.se/resolve?urn=urn:nbn:se:liu:diva-91729 


\title{
Characterization of plasma chemistry and ion energy in cathodic arc plasma from Ti-Si cathodes of different compositions
}

\author{
A. O. Eriksson, ${ }^{\text {a) }}$ I. Zhirkov, M. Dahlqvist, J. Jensen, L. Hultman, and J. Rosen \\ Thin Film Physics Division, Department of Physics, Chemistry and Biology (IFM), Linköping University, \\ SE-581 83 Linköping, Sweden
}

(Received 11 January 2013; accepted 2 April 2013; published online 29 April 2013)

\begin{abstract}
Arc plasma from Ti-Si compound cathodes with up to 25 at. \% Si was characterized in a DC arc system with respect to chemistry and charge-state-resolved ion energy. The plasma ion composition showed a lower $\mathrm{Si}$ content, diverging up to 12 at. \% compared to the cathode composition, yet concurrently deposited films were in accordance with the cathode stoichiometry. Significant contribution to film growth from neutrals is inferred besides ions, since the contribution from macroparticles, estimated by scanning electron microscopy, cannot alone account for the compositional difference between cathode, plasma, and film. The average ion charge states for Ti and $\mathrm{Si}$ were higher than reference data for elemental cathodes. This result is likely related to $\mathrm{TiSi}_{\mathrm{x}}$ phases of higher cohesive energies in the compound cathodes and higher effective electron temperature in plasma formation. The ion energy distributions extended up to $\sim 200$ and $\sim 130 \mathrm{eV}$ for $\mathrm{Ti}$ and $\mathrm{Si}$, respectively, with corresponding average energies of $\sim 60$ and $\sim 30 \mathrm{eV}$. These averages were, however, not dependent on Si content in the cathode, except for 25 at. \% Si where the average energies were increased up to $72 \mathrm{eV}$ for Ti and $47 \mathrm{eV}$ for Si. C 2013 AIP Publishing LLC. [http://dx.doi.org/10.1063/1.4802433]
\end{abstract}

\section{INTRODUCTION}

Arc deposition of multi-component thin films is today a common method to synthesize wear resistant, decorative, and functional coatings. ${ }^{1}$ By selecting material combinations in multinary systems, effects such as incommensurable phases, grain refinement, and pathways for spinodal decomposition can be exploited. ${ }^{2}$ The coating technology can be adapted to synthesize multi-element films, for example, by simultaneous deposition from several plasma sources or incorporation of reactive gases. One common approach is to mix two or more film-forming elements in a compound target from which plasma is generated. Examples include the use of Ti-Al cathodes for deposition of Ti-Al-N, ${ }^{3}$ Al-Cr cathodes for Al-Cr-N, ${ }^{4}$ and Ti-Si cathodes for Ti-Si- $\mathrm{N}^{5}$ deposition. There are, however, only a few studies addressing the effects of compound targets on plasma composition and properties..$^{6-10}$ For example, Sasaki and Brown investigated a range of mostly binary cathode materials (including $\mathrm{SiC}, \mathrm{TiC}, \mathrm{TiN}, \mathrm{TiO}_{2}, \mathrm{UN}, \mathrm{UC}$ $\mathrm{ZrC}$, and $\mathrm{LaB}_{6}$ ) to conclude that non-metallic ions of $\mathrm{C}, \mathrm{N}$, and $\mathrm{O}$ were generated, albeit in lower amounts than the corresponding cathode stoichiometry. ${ }^{6}$ Furthermore, for Ti-Hf cathodes, the plasma composition was found to be in closer, though not perfect, agreement with the cathode stoichiometry ${ }^{7}$ and the data was the basis for development of generalized Saha equations for multiple elements. ${ }^{8}$ Bilek et al. determined for Ti-Al cathodes that the properties of the lower meltingpoint element, Al, dominated the discharge until the cathode Ti content was as high as 75 at. \%. ${ }^{9}$ Through consideration of W-C-Co, Cu-Cr, and Ti-Cu cathodes, Savkin et al. suggested

\footnotetext{
a) Author to whom correspondence should be addressed. Present address: OC Oerlikon Balzers AG, Iramali 18, 9496 Balzers, Liechtenstein. Electronic mail: anders.o.eriksson@oerlikon.com. Telephone: +423 388 7726. Fax: +4233885413 .
}

that the cathode spot on a compound cathode attains an electron temperature that is the weighted average of the electron temperatures for the corresponding pure elements. ${ }^{10}$ This has implications for the charge state distribution of the cathode constituents. Higher charge states may form for the cathode constituent exhibiting lower electron temperature in the pure elemental cathode, while the highest charge states may not form for the high electron temperature component. ${ }^{10}$ These studies contribute to an emerging description of arc plasma generation from compound cathodes. However, there are not yet any generalized models to predict plasma properties, such as charge states and energies, comparable to, e.g., the cohesive energy rule for elemental cathodes. There is also a wide range of cathode material combinations of technological and scientific interest remaining to be studied. We show in this publication that the constituent phases of the cathode are important for plasma generation in addition to the constituting elements.

Here, we use charge-state resolved mass spectrometry to characterize arc plasma from Ti-Si compound cathodes. This type of cathodes has been used successfully to grow Ti-Si$\mathrm{N}^{5}$ and Ti-Si-C- $\mathrm{N}^{11}$ thin films. By characterizing plasma composition, ion energy, and ion charge state, we provide a base for improved understanding of the correlation between cathode, plasma, and film, and further control of plasmabased thin film synthesis.

\section{EXPERIMENTAL DETAILS}

\section{A. Plasma analysis}

The experiments were performed using a deposition system equipped with an industrial scale DC arc source (Ionbond) for $63 \mathrm{~mm}$ diameter cathodes. Ti and Ti-Si cathodes produced by powder metallurgy ${ }^{12,13}$ were used, of composition 0 at. \% (i.e., pure Ti), 7, 10, 15, and 25 at. \% Si. The 
cathodes were used for at least $10 \mathrm{~min}$ prior to measurements, to remove eventual surface contaminants and achieve steady-state conditions. The arc source was operated at $65 \mathrm{~A}$ arc current at a base pressure around $10^{-6}$ Torr. A massenergy-analyzer (MEA, Hiden Analytics model EQP) was placed in front of the arc source with the orifice $(50 \mu \mathrm{m}$ diameter) about $33 \mathrm{~cm}$ from the cathode surface. For each cathode, the plasma was characterized through mass-scans at fixed ion energy and energy-scans at fixed mass-to-charge ratio for all ions of $\mathrm{Ti}$ and $\mathrm{Si}$. The major isotope was measured in all cases, except for $\mathrm{Ti}^{2+}$, where the isotope at $23 \mathrm{amu} /$ charge (doubly charged ion of the $46 \mathrm{amu}$ isotope) was selected to avoid detector saturation. This was compensated for numerically in the data analysis using the natural isotope distribution, ${ }^{14}$ which was also verified experimentally in our system by measuring the relative intensity of the singly charged ions of the isotopes between 46 and $50 \mathrm{amu}$, as well as the corresponding doubly charged ions of the isotopes between 23 and $25 \mathrm{amu}$. The energy scans were recorded in steps of $1 \mathrm{eV} /$ charge up to $200 \mathrm{eV} /$ charge to capture the entire ion energy distribution (IED). Each IED was recorded at least twice to ensure consistency of the data. Over time the MEA orifice becomes coated and the measured intensity reduced as an effect of reduced orifice size. This effect was not significant for the set of measurements performed for one cathode, as determined by repeat measurements, which also confirms that steady state conditions were sampled. The scans acquired for a particular cathode can thus readily be compared. To determine the plasma composition, the IEDs were integrated to obtain areas proportional to the number of ions of each species. Integral average energies, $\mathrm{E}_{\mathrm{avg}}$, were also calculated according to

$$
E_{\text {avg }}=\frac{\int I \cdot E \cdot d E}{\int I \cdot d E} .
$$

For comparisons between different cathodes, the analysis relies on relative data obtained separately for each cathode. The average ion energies and ion charge states were found to be reproducible within $5 \%$.

\section{B. Film growth}

Films were deposited from the 10 and 25 at. \% Si cathodes by fixing a $\mathrm{MgO}$ substrate at the front end of the plasma analyzer at floating potential. To ensure steady arc operation during film growth for $20 \mathrm{~min}, \sim 10 \mathrm{sccm}$ of Ar was introduced during film growth, up to a pressure of $5 \times 10^{-4}$ Torr. The plasma characterization presented in this work was performed at base pressure. However, additional characterization with the $\mathrm{Ti}_{90} \mathrm{Si}_{10}$ and $\mathrm{Ti}_{75} \mathrm{Si}_{25}$ cathodes in $\mathrm{Ar}$ at $5 \times 10^{-4}$ Torr shows that the plasma composition was not significantly influenced and the film and plasma properties can hence be compared.

\section{Characterization of cathodes and films}

The phase structure of the cathodes was examined by X-ray diffractometry (XRD) using a PANalytical X'PERT $\mathrm{X}$-ray diffractometer with a line-focus $\mathrm{Cu}_{\alpha} \mathrm{X}$-ray source, where $\theta-2 \theta$ scans were recorded in the $2 \theta$-range from $25^{\circ}$ to $140^{\circ}$. Surface morphology and composition of films and cathodes was characterized using a LEO 1550 scanning electron microscope (SEM) equipped for energy dispersive $\mathrm{X}$-ray spectroscopy (EDS). The film areal coverage of macroparticles was determined from SEM images of $90000 \mu \mathrm{m}^{2}$ with a resolution of $0.125 \mu \mathrm{m} /$ pixel for each film. Film composition was also determined through time-of-flight energy elastic recoil detection analysis (TOF-E ERDA), using a $36 \mathrm{MeV}^{127} \mathrm{I}^{8+}$ ion beam at $22.5^{\circ}$ incidence angle relative to the surface and $45^{\circ}$ recoil angle. ${ }^{15}$ The resulting time-of-flight versus recoil energy spectra was evaluated using the CONTES code. ${ }^{16}$

\section{Calculational details}

The cohesive energy $E_{c o h}$ of a solid phase represents the energy required to break the solid $\left(E_{\text {solid }}\right)$ into isolated atomic species $\left(E_{\text {isolated }}^{A}\right)$ according to

$$
E_{\text {coh }}=E_{\text {solid }}-\sum_{A} E_{\text {isolated }}^{A},
$$

where $A$ represents the different atoms of the solid phase. The calculations of cohesive energies for Ti-Si phases were based on density-functional theory within the generalized gradient approximation $(\mathrm{GGA})^{17}$ using the projector augmented wave $(\mathrm{PAW})^{18}$ method implemented in VASP. ${ }^{19,20}$ For solid phases, $k$-point sampling of the Brillouin zone was performed using a Monkhorst-Pack scheme ${ }^{21}$ with a $k$-mesh chosen to achieve a convergence of the total energy of less than $0.2 \mathrm{meV}$ per atom. An energy cutoff of $400 \mathrm{eV}$ was used in the expansion of the plane wave functions. Each phase was optimized with respect to cell volume, $c / a$ ratio, as well as internal parameters. For isolated atomic species, a spinpolarized functional was used with atoms in their groundstate spin configurations. Convergence tests show that an orthorhombic supercell with sides of $\sim 20 \AA$ is sufficient to converge the total energy to less than $0.2 \mathrm{meV} /$ atom.

\section{RESULTS AND DISCUSSION}

\section{A. Charge-state resolved ion energy}

$\mathrm{Ti}$ and $\mathrm{Si}$ ions of charge states $1+, 2+$, and $3+$ were detected in the plasma from all Ti-Si cathodes. No significant intensity was recorded for charge states of $4+$ and higher. Figure 1 exemplifies IEDs as obtained from the $\mathrm{Ti}_{75} \mathrm{Si}_{25}$ cathode. The distributions have a high-energy tail, measurable up to $200 \mathrm{eV}$ for $\mathrm{Ti}^{2+}$. There is a sharp peak in energy below $6 \mathrm{eV}$, which, even though of low intensity is particularly evident for $\mathrm{Si}$ ions. The origin of these low energy ions is beyond the scope of the present investigation. However, they individually only constitute up to $2 \%$ of the total IED, and hence do not significantly influence the results presented here.

\section{B. Plasma composition}

To determine the plasma composition, the integrated area of the IEDs was calculated and summarized for all $\mathrm{Ti}$ 

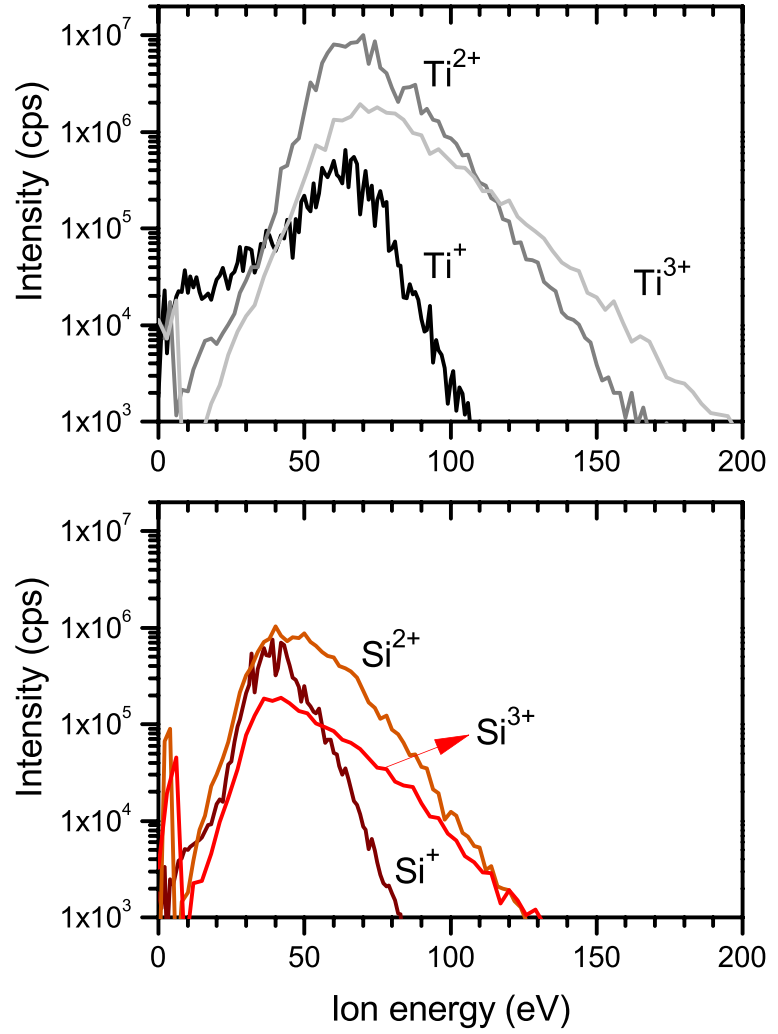

FIG. 1. Ion energy distributions of the plasma from a $\mathrm{Ti}_{75} \mathrm{Si}_{25}$ cathode.

and $\mathrm{Si}$ ions. As seen in Figure 2, the $\mathrm{Si}$ ion content is between 0.5 and 12 at. \% below the corresponding cathode concentration, an effect more pronounced for the cathodes of higher Si content. To investigate the origin of this discrepancy, thin films were grown using the $\mathrm{Ti}_{90} \mathrm{Si}_{10}$ or the $\mathrm{Ti}_{75} \mathrm{Si}_{25}$ cathodes. The $\mathrm{Si} / \mathrm{Ti}$ ratio in the films, as determined by EDS and ERDA, was in good agreement with the composition of the cathodes, see Table I. The nominal cathode composition was also verified (within measurement

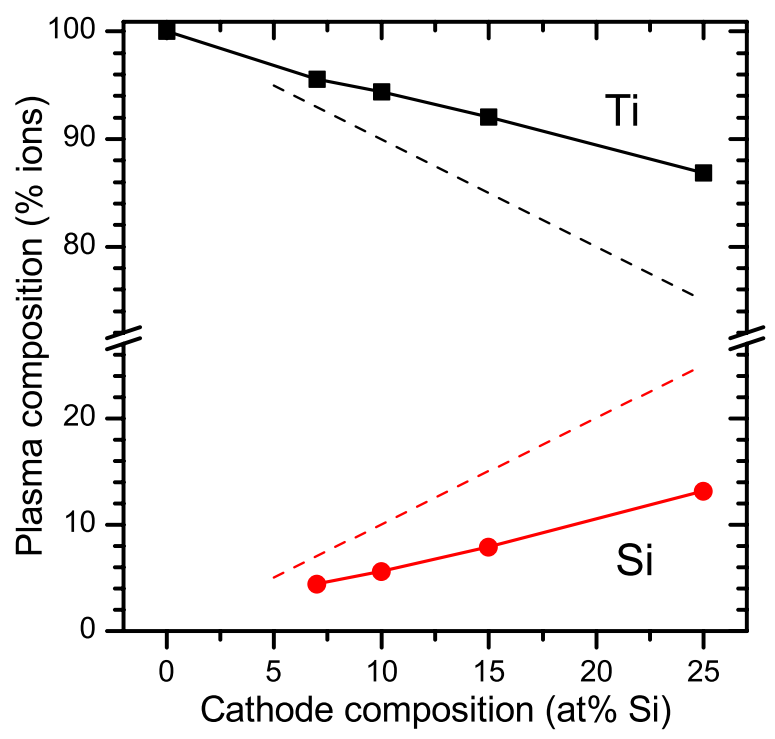

FIG. 2. Plasma composition (ionic part) as a function of the nominal cathode composition. The dashed lines indicate 1:1 correspondence between cathode and plasma composition.
TABLE I. Comparison of distribution between $\mathrm{Ti}$ and $\mathrm{Si}$, measured for cathode, plasma, and films. All values are in at. $\%$.

\begin{tabular}{|c|c|c|c|c|c|c|c|c|}
\hline \multirow[b]{2}{*}{ Cathode } & \multicolumn{2}{|c|}{ Cathode (EDS) } & \multicolumn{2}{|c|}{ Plasma (MEA) } & \multicolumn{2}{|c|}{ Film (EDS) } & \multicolumn{2}{|c|}{ Film (ERDA) } \\
\hline & $\mathrm{Ti}$ & $\mathrm{Si}$ & $\mathrm{Ti}$ & $\mathrm{Si}$ & $\mathrm{Ti}$ & $\mathrm{Si}$ & $\mathrm{Ti}$ & $\mathrm{Si}$ \\
\hline $\mathrm{Ti}_{90} \mathrm{Si}_{10}$ & 92.0 & 8.0 & 94.4 & 5.6 & 91.0 & 9.0 & 91.2 & 8.8 \\
\hline $\mathrm{Ti}_{75} \mathrm{Si}_{25}$ & 75.9 & 24.1 & 86.8 & 13.2 & 77.3 & 22.7 & 76.8 & 23.2 \\
\hline
\end{tabular}

accuracy) by EDS. The discrepancy between cathode and film composition on one hand, and plasma ion composition on the other, suggests that there is mass transport besides the ions, such as by neutrals or macroparticles, of a deviating composition compared to the cathode. Since both plasma ion analysis and film growth were performed at the same position in the deposition system, the comparison will be based on the same portion of the anisotropic angular distributions for ion and macroparticle emission. ${ }^{22-24}$ The film composition can be affected by ion-surface interaction including resputtering of the growing film. However, the anticipated effect would be preferential resputtering of the lighter element, ${ }^{25}$ which would give a $\mathrm{Si}$ content lower than the Si flux to the substrate. Hence, we conclude that the plasma-film compositional discrepancy is not primarily related to film growth, and proceed to consider potential non-ion contributions from the plasma, which are not captured by the MEA.

\section{Macroparticle formation}

The substantially (up to 12 at. \%) higher Si content of films compared to the ionic plasma infers that there is significant contribution to film growth from neutral species, which are not captured by the MEA. Inherent to arc evaporation is the generation of macroparticles, which have no net charge and will be incorporated in the growing film in the present configuration (no filter). To obtain an estimate for the macroparticle contribution to film growth, the total area covered by visible macroparticles in surface SEM micrographs was quantified, as exemplified in Figure 3. The initially deposited macroparticles will often be overgrown through nucleation and film growth on top to form surface defects of larger area, see, e.g., Refs. 26 and 27. This may cause the areal coverage to be overestimated in relation to the volume contribution of macroparticles. Even for assumed spherical particles, without overgrowth, the volume fraction is on average smaller than the projected area. For example, a sphere inscribed in a cube will occupy $52 \%$ of the volume but fill up $79 \%$ of the projected area. Furthermore, macroparticles will reach the film continuously, and show the full projected area until buried to at least $50 \%$ while the volume contribution is relatively small, see Figure 4. This compensates for the macroparticles showing a limited part of the projected area when buried to more than $50 \%$, i.e., when the volume contribution is comparatively large. Therefore, it is fair to assess an upper limit for the volume contribution of macroparticles to the film of $10 \%$ and $8 \%$, based on the surface coverage determined by plan-view SEM imaging of particles for films deposited from $\mathrm{Ti}_{90} \mathrm{Si}_{10}$ and $\mathrm{Ti}_{75} \mathrm{Si}_{25}$ cathodes, respectively. 


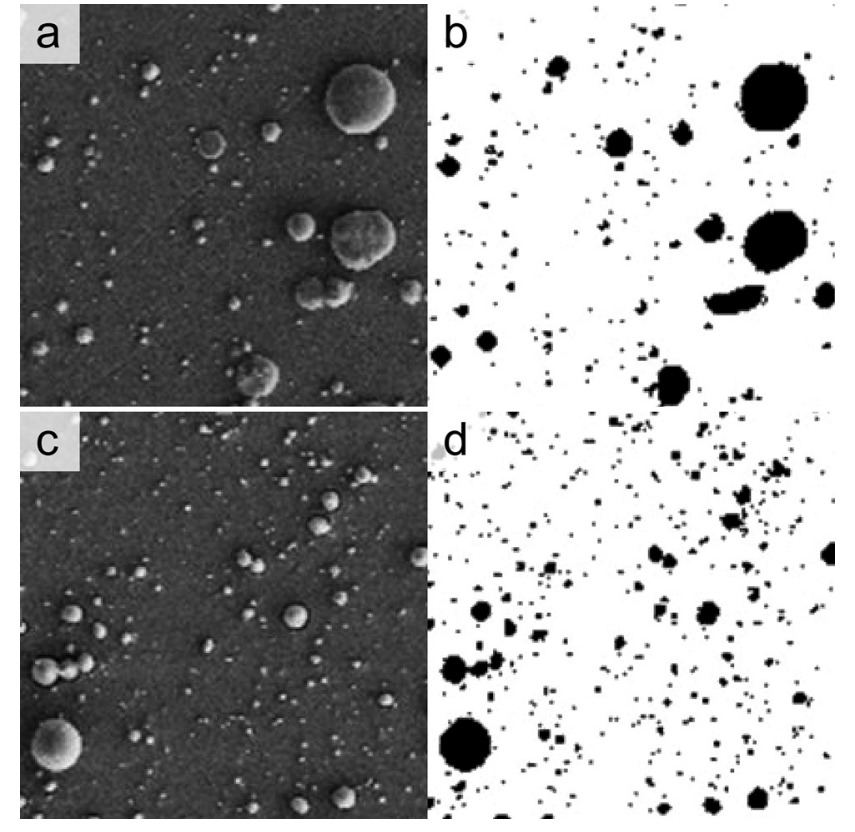

FIG. 3. SEM micrographs, and corresponding binary pictures of films deposited from (a) and (b) $\mathrm{Ti}_{90} \mathrm{Si}_{10}$ cathodes, and (c) and (d) $\mathrm{Ti}_{75} \mathrm{Si}_{25}$ cathodes, respectively.

If macroparticles as transfer mechanism from cathode to film should account for the differences between plasma and film composition, the macroparticles must have higher Si content than the global cathode composition. This can be seen considering that the $\mathrm{Si}$ content in a unit volume of the film $C_{S i}^{f}$ will be related to the $\mathrm{Si}$ fraction in plasma ions, $C_{S i}^{i}$ and macroparticles, $C_{S i}^{m p}$, according to
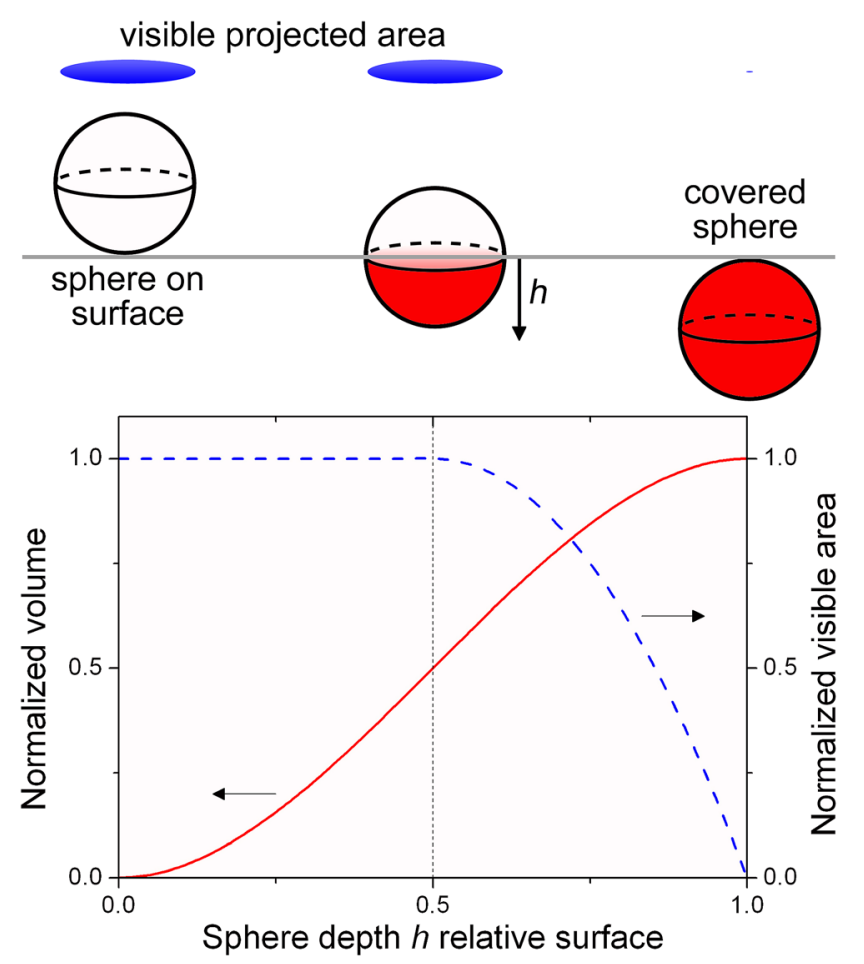

FIG. 4. Schematic of volume and projected area of a sphere buried to different depth $h$ in a film. The projected area shows the maximum value until buried to half the height, while the volume contribution is symmetric around half the sphere volume.

$$
C_{S i}^{f}=(1-x) C_{S i}^{i}+x C_{S i}^{m p}
$$

for a macroparticle fraction $x$ of the atoms contributed to film growth defined as

$$
x=\frac{N_{T i}^{m p}+N_{S i}^{m p}}{N_{S i}^{i}+N_{S i}^{m p}+N_{T i}^{i}+N_{T i}^{m p}},
$$

where

$$
C_{S i}^{f}=\frac{N_{S i}^{f}}{N_{S i}^{f}+N_{T i}^{f}}, C_{S i}^{i}=\frac{N_{S i}^{i}}{N_{S i}^{i}+N_{T i}^{i}}, \text { and } C_{S i}^{m p}=\frac{N_{S i}^{m p}}{N_{S i}^{m p}+N_{T i}^{m p}} .
$$

$N$ denotes number of atoms/ions, for example, in a unit volume, or of the plasma ions counted in the MEA. To compensate for the fact that $C_{S i}^{i}<C_{S i}^{f}$ as shown in Table $\mathrm{I}$, it is required that $C_{S i}^{m p}$ is larger than $C_{S i}^{i}$, to what extent depending on the macroparticle fraction $x$, as these are the only terms in the weighted sum in Eq. (3), and $0 \leq \mathrm{x} \leq 1$ according to the definition in Eq. (4). To see whether Si-rich macroparticles are feasible, the structure of the cathodes needs to be considered.

The as-received cathodes consist of a phase mixture of $\mathrm{Ti}, \mathrm{TiSi}_{2}, \mathrm{Ti}_{5} \mathrm{Si}_{3}$, and TiSi as determined by XRD, see Figure 5(a). The elements are unevenly distributed in the cathodes as shown by EDS mapping in Figures 5(b) and 5(c). The area of pure $\mathrm{Ti}$ in Figure 5(b) is represented by the dark area of no $\mathrm{Si}$ in Figure 5(c), while the $\mathrm{TiSi}_{\mathrm{x}}$ phases have counts in
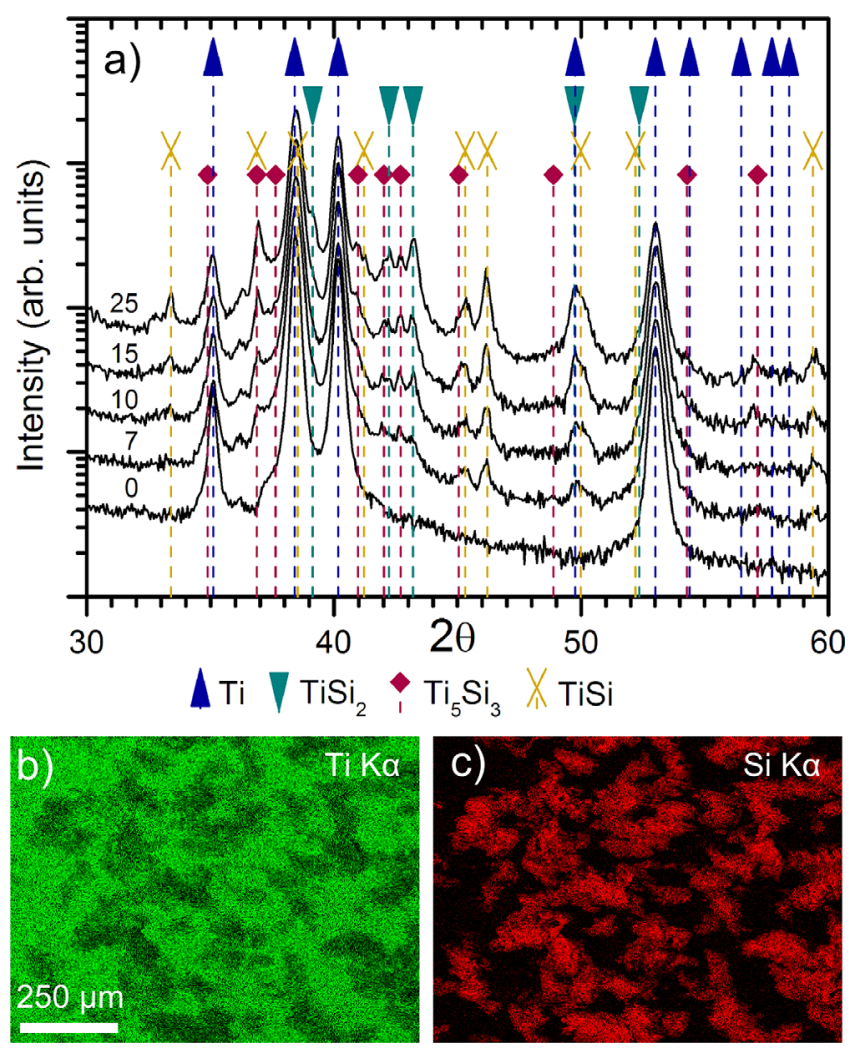

FIG. 5. (a) XRD pattern from the as-received Ti-Si cathodes, where the numbers on the left side correspond to at. $\% \mathrm{Si}$ in the cathodes. EDSmapping of (b) $\mathrm{Ti}$ and (c) $\mathrm{Si}$ on the surface of a $\mathrm{Ti}_{75} \mathrm{Si}_{25}$ cathode. 
both Figures 5(b) and 5(c). This suggests that the $\mathrm{TiSi}_{\mathrm{x}}$ phases are separate from the Ti phase after the powder metallurgical production process. Heating of the cathode surface due to the cathode spot might cause an intermixing or formation of different phases even in a non-reactive environment. The phase composition and distribution will determine the conditions for arc spots at the cathode surface. XRD analysis (not presented here) of worn cathodes showed a phase mixture similar to the as-received cathodes. However, quantification of changes in phase composition upon plasma generation is not attempted due to rough cathode surfaces, in turn resulting in reduced XRD peak intensity as well as peak broadening. Previous work on similar Ti-Si cathodes has also identified $\mathrm{Ti}$ and $\mathrm{Ti}_{5} \mathrm{Si}_{3}$ phases in virgin cathodes, as well as in cathodes worn in $\mathrm{N}_{2}$ atmosphere where also nitrided phases were formed on the surface. ${ }^{28}$

Macroparticles are formed in the molten pool at the arc spot. In studies with elemental cathodes, increased abundance of macroparticles has been reported for lower melting point materials when comparing $\mathrm{Cu}$ and $\mathrm{Cd},{ }^{29}$ as well as considering a range of metals ( $\mathrm{W}, \mathrm{Pt}, \mathrm{Ni}, \mathrm{Cu}, \mathrm{Ag}$, and $\mathrm{Pd}){ }^{30}$ However, a monotonic relationship could not be established, suggesting that macroparticle production is more complex than just a function of one material parameter. ${ }^{30}$ In the present work, the complexity is increased further by the inhomogeneity of the cathodes. According to the Ti-Si phase diagram, ${ }^{31} \mathrm{TiSi}$ and $\mathrm{TiSi}_{2}$ have lower melting points than pure Ti: $1570{ }^{\circ} \mathrm{C}$ and $1480{ }^{\circ} \mathrm{C}$ compared to $1670{ }^{\circ} \mathrm{C}$. Easier melting and higher macroparticle generation may thus be expected from the areas of the cathode containing the TiSi and $\mathrm{TiSi}_{2}$ phases. These macroparticles will likely have higher Si content than the global cathode composition when originating from the melt of these Si-rich phases. However, for the $\mathrm{Ti}_{75} \mathrm{Si}_{25}$ cathode, the contribution of macroparticles determined by SEM is too low to be the only factor to explain the compositional difference between cathode/film and plasma. A lower limit of $11 \%$ macroparticle contribution to the film, i.e., $x$ equal to 0.11 in Eq. (4), would be required if the macroparticles were pure Si. This is calculated from Eq. (3) with plasma and film composition according to Table I. As discussed above, $\mathrm{x}$ is defined as the ratio of film forming atoms originating from macroparticles, which would equal the volume contribution to the film if the film density is independent of composition. In practice, the molar volume of $\mathrm{Si}$ is larger than $\mathrm{Ti}$, which would increase the volume needed from pure Si macroparticles. Furthermore, it is hard to foresee a $\mathrm{Si}$ composition higher than 67 at. \% Si, corresponding to the most $\mathrm{Si}$-rich phase $\left(\mathrm{TiSi}_{2}\right)$ in the cathodes. The effect of neutral atoms contributing to film growth must therefore be considered in addition to macroparticles.

\section{Neutrals}

The explosive arc process produces plasma with high degree of ionization. The neutral fraction of the total heavy particle (i.e., ions and neutrals) density has been calculated using the Saha equations to $0.042 \%$ and $1.1 \%$ for $\mathrm{Ti}$ and $\mathrm{Si}$, respectively. ${ }^{32}$ Neutrals can, however, form in significant amounts from other sources in the arc evaporation process, ${ }^{1}$ though the evidence is often indirect owing to experimental challenges to measure neutrals in plasma. In particular, self sputtering has been shown by film thickness measurements for arc deposition of $\mathrm{Zr}$ and $\mathrm{Au} .{ }^{33}$ The presence of neutrals has been inferred from charge state reduction after ignition in pulsed arcs of $\mathrm{Al}, \mathrm{Mg}, \mathrm{Cu}, \mathrm{Pb}, \mathrm{Bi}$, and $\mathrm{Mo}$. The reduction was enhanced when additional surfaces were present, amplifying plasma-wall interactions as a neutral source. ${ }^{34}$ Evaporation from macroparticles during flight has also been suggested as contribution to neutral vapor density, which is significant during the off-periods in pulsed arc evaporation of $\mathrm{Cu}^{35}$ Additionally, modeling the solidification of previously active arc spots on the cathode surface has shown the solidification time to be about one order of magnitude greater than the cathode spot formation time. ${ }^{36}$ While cooling in the molten state, evaporation of cathode material will occur as a significant source of neutrals, ${ }^{34}$ depending on the vapor pressure. Formation of neutrals is thus to be expected in our setup. Similar to macroparticles, neutrals can be one factor behind the compositional difference between plasma and film if they are rich in Si. Evaporation of neutrals from molten cathode material is determined by the vapor pressure of the elements. The vapor pressure for $\mathrm{Si}$ is higher than $\mathrm{Ti}^{37}$ which suggests that possible neutral emission by vaporization may be preferential to Si. In combination with molten Ti-Si phases rich in $\mathrm{Si}$, this effect could be amplified and may partially explain the observed cathode-plasma compositional discrepancy.

\section{E. Effect of alloying on ion charge states and ion energies}

The average ion charge state and ion energies calculated from the IEDs are presented in Figure 6. The average charge state for ions from the pure Ti cathode (1.89) is in reasonable agreement with the literature value $2.03 .{ }^{1}$ The average charge state of $\mathrm{Ti}$ increases moderately, up to $15 \%$, as an effect of cathode alloying, while the trend for $\mathrm{Si}$ is reverse, the average charge state decreases from 2.1 to 1.9 with increasing Si content. However, throughout the concentration range investigated, the average charge state is well above the reference values for pure Si (1.39). ${ }^{1}$ For elemental cathodes, the empirical cohesive energy rule establishes a positive correlation between the cohesive energy of the cathode material and ion charge state. ${ }^{38}$ In our case, since the cathodes consist of two elements as a mixture of several phases that are unevenly distributed, a single cohesive energy for the cathodes cannot be established. Calculations show that the intermetallic Ti-Si phases all have cohesive energies which are higher than the pure elements, see Figure 7. Reference values of cohesive energies of $\mathrm{Ti}$ and $\mathrm{Si}$ are also shown for comparison in the figure. Worth noting is the somewhat higher values for calculations based on the local density approximation (LDA) as compared the GGA. This effect can be related to overestimated binding energy known for LDA, ${ }^{39}$ However, the trend of cohesive energies for the $\mathrm{TiSi}_{\mathrm{x}}$ phases can be reproduced by both approximations. The increasing charge state of Ti in Figure 6 can now be interpreted based on the cohesive energies. With higher $\mathrm{Si}$ 
content in the cathode, an increasing fraction of the $\mathrm{Ti}$ ions will originate from erosion of Ti-Si phases where the charge state would be higher according to the cohesive energy rule, assuming the rule is applicable also for binary phases. For $\mathrm{Si}$, the increased average charge state relative to reference data can be viewed as an effect of the higher cohesive energies for the Si-containing phases in the cathodes. The decreasing charge states (from 2.1 to 1.9) with increasing cathode Si content as observed in Figure 6 may reflect a change in the relative amount of the $\mathrm{TiSi}_{\mathrm{x}}$ phases, if so in favor of $\mathrm{TiSi}_{2}$ and $\mathrm{TiSi}$ with lower cohesive energies. Our data are thus largely consistent with a generalized interpretation of the cohesive energy rule, where plasma will be generated concurrently from several phases.

A different rationalization for altered charge state in compound cathodes has been proposed based on the suggestion that the electron temperature would attain a weighted average of the pure element electron temperatures for the contributing materials. ${ }^{10}$ This has implications for the charge state distribution, where higher charge states may form for the cathode constituent exhibiting lower electron temperature in the pure elemental cathode, while the highest charge states may not form for the high electron temperature component. ${ }^{10}$ The electron temperatures for $\mathrm{Ti}$ and $\mathrm{Si}$ in pure form are 3.2 and $2.0 \mathrm{eV}$, respectively. An average between these values would justify the higher charge states we observe for $\mathrm{Si}$, but not the slightly increased charge states for Ti.

The average ion energies for $\mathrm{Ti}$ and $\mathrm{Si}$ are close to the reference values $\sim 60$ and $\sim 30 \mathrm{eV}$, respectively, for a Si content in the cathode of up to 15 at. \%, see Figure 6. Higher average ion energies, 72 and $47 \mathrm{eV}$, respectively, are obtained in plasma from the $\mathrm{Ti}_{75} \mathrm{Si}_{25}$ cathode. The ion kinetic energies

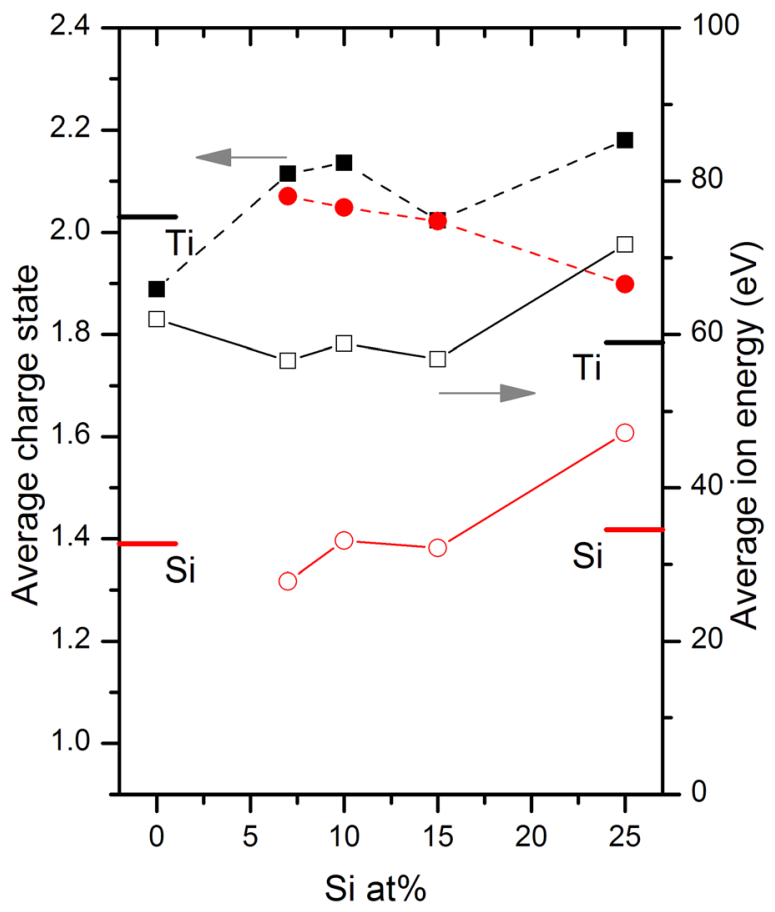

FIG. 6. Average charge state (filled symbols), average ion energy (open symbols) as function of cathode Si content. The lines on the vertical axis represent literature values of charge state and energy, from Ref. 1.

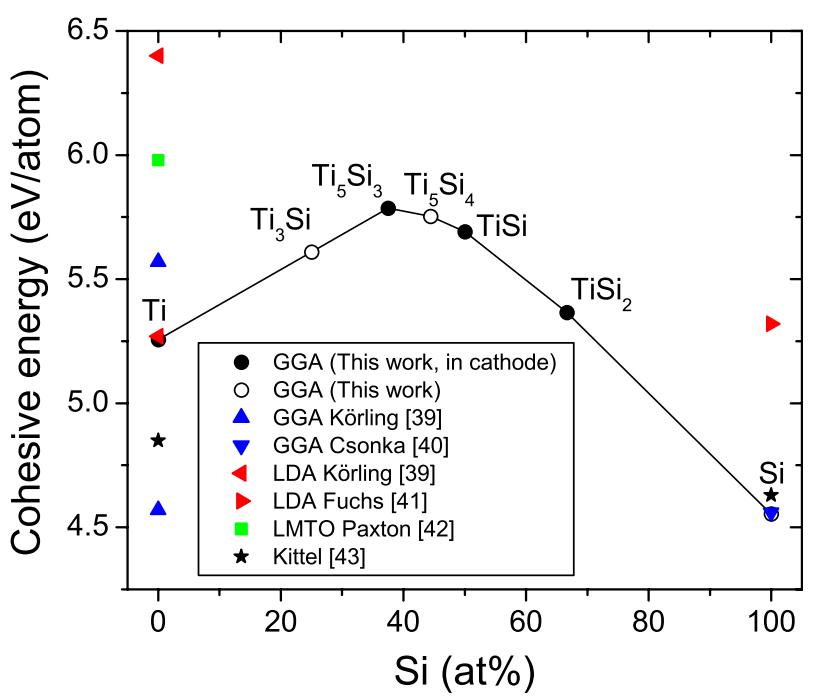

FIG. 7. Calculated cohesive energies of Ti-Si phases (circles). Filled circles represent phases identified in the cathodes of the present investigation. Values from theoretical work and Kittel are given for reference. ${ }^{39-43}$

have been found to also correlate to the cathode cohesive energy, ${ }^{38}$ which would predict higher energies with increasing fraction of $\mathrm{TiSi}_{\mathrm{x}}$ phases. The effect is, however, not as readily detectable compared to the average charge states. Both ion energies and ion charge states are important parameters for controlled film growth. We show that both these parameters most likely depend on composition as well as the phase structure of the cathodes.

\section{CONCLUSIONS}

The arc plasma generation from Ti-Si compound cathodes has been characterized with respect to ion composition and ion energy. The proportion of $\mathrm{Si}$ in the ionic part of the plasma is up to 12 at. \% lower than the corresponding cathode content, while composition of concurrently grown films agrees well with the cathode composition. This suggests that contributions to film growth besides plasma ions are important in the Ti-Si system. The presence of cathode intermetallic Ti-Si phases of high cohesive energy results in higher charge states compared to reference data for $\mathrm{Ti}$ and $\mathrm{Si}$, which may be explained by applying the cohesive energy rule also for binary phases. Furthermore, at 25 at. \% Si cathode composition there is a notable increase in ion energies relative to reference data for the pure elements.

\section{ACKNOWLEDGMENTS}

This work was funded by the VINN Excellence center on Functional Nanoscale Materials (FunMat), and the European Research Council under the European Community's Seventh Framework Programme (FP7/2007-2013)/ERC Grant agreement No. [258509]. Uppsala University is acknowledged for access to the Tandem Laboratory for ERDA-measurements. The calculations were carried out using supercomputer resources provided by the Swedish National Infrastructure for Computing (SNIC). 
${ }^{1}$ A. Anders, Cathodic Arcs, 1st ed. (Springer, New York, 2008).

${ }^{2}$ P. H. Mayrhofer, C. Mitterer, L. Hultman, and H. Clemens, Prog. Mater. Sci. 51, 1032-1114 (2006).

${ }^{3}$ S. PalDey and S. C. Deevi, Mater. Sci. Eng., A 342, 58-79 (2003).

${ }^{4}$ H. Willmann, P. H. Mayrhofer, P. O. A. Persson, A. E. Reiter, L. Hultman, and C. Mitterer, Scr. Mater. 54, 1847-1851 (2006).

${ }^{5}$ A. Flink, M. Beckers, J. Sjölen, T. Larsson, S. Braun, L. Karlsson, and L. Hultman, J. Mater. Res. 24, 2483 (2009).

${ }^{6}$ J. Sasaki and I. G. Brown, J. Appl. Phys. 66, 5198-5203 (1989).

${ }^{7}$ J. Sasaki, K. Sugiyama, X. Yao, and I. Brown, J. Appl. Phys. 73, 7184-7187 (1993).

${ }^{8}$ T. Schülke and A. Anders, IEEE Trans. Plasma Sci. 27, 911-914 (1999).

${ }^{9}$ M. M. M. Bilek, P. J. Martin, and D. R. McKenzie, J. Appl. Phys. 83, 2965-2970 (1998).

${ }^{10}$ K. P. Savkin, G. Y. Yushkov, A. G. Nikolaev, E. M. Oks, and G. Y. Yushkov, Rev. Sci. Instrum. 81, 02A501 (2010).

${ }^{11}$ L. J. S. Johnson, L. Rogström, M. P. Johansson, M. Odén, and L. Hultman, Thin Solid Films 519, 1397-1403 (2010).

${ }^{12} \mathrm{P}$. Wilhartitz, S. Schönauer, and P. Polcik, "Method for producing an evaporation source," EP Patent 1335995, 29 September 2004.

${ }^{13}$ G. Korb, "Process for the manufacture of a target for cathodic sputtering," U.S. Patent 4,752,335, 29 June, 1988.

${ }^{14}$ CRC Handbook of Chemistry and Physics, 92 nd ed., edited by D. R. Lide (CRC Press, Boca Raton, FL, 2012), Internet Version 2012.

${ }^{15}$ H. J. Whitlow, G. Possnert, and C. S. Petersson, Nucl. Instrum. Methods Phys. Res. B 27, 448-457 (1987).

${ }^{16}$ M. S. Jansson, "CONTES, Conversion of time-energy spectra-a program for ERDA data analysis," Internal Report, Uppsala University, 2004.

${ }^{17}$ J. P. Perdew, K. Burke, and M. Ernzerhof, Phys. Rev. Lett. 77, 3865-3868 (1996).

${ }^{18}$ P. E. Blöchl, Phys. Rev. B 50, 17953-17979 (1994).

${ }^{19}$ G. Kresse and J. Hafner, Phys. Rev. B 48, 13115-13118 (1993).

${ }^{20}$ G. Kresse and J. Hafner, Phys. Rev. B 49, 14251-14269 (1994)

${ }^{21}$ H. J. Monkhorst and J. D. Pack, Phys. Rev. B 13, 5188-5192 (1976).
${ }^{22}$ A. G. Nikolaev, G. Y. Yushkov, K. P. Savkin, and E. M. Oks, "Angular Distribution of Ions in a Vacuum Arc Plasma With Single-Element and Composite Cathodes" IEEE Trans. Plasma Sci. (in press).

${ }^{23}$ A. G. Nikolaev, G. Y. Yushkov, K. P. Savkin, and E. M. Oks, Rev. Sci. Instrum. 83, 02A503-3 (2012).

${ }^{24}$ A. Anders and G. Y. Yushkov, Appl. Phys. Lett. 80, 2457-2459 (2002).

${ }^{25}$ A. O. Eriksson, J. Q. Zhu, N. Ghafoor, M. P. Johansson, J. Sjölén, J. Jensen, M. Odén, L. Hultman, and J. Rosén, Surf. Coat. Technol. 205, 3923-3930 (2011).

${ }^{26}$ I. Petrov, P. Losbichler, D. Bergstrom, J. E. Greene, W. D. Münz, T. Hurkmans, and T. Trinh, Thin Solid Films 302, 179-192 (1997).

${ }^{27}$ M. Pohler, R. Franz, J. Ramm, P. Polcik, and C. Mitterer, Surf. Coat. Technol. 206, 1454-1460 (2011).

${ }^{28}$ J. Q. Zhu, A. Eriksson, N. Ghafoor, M. P. Johansson, J. Sjölén, L. Hultman, J. Rosén, and M. Odén, J. Vac. Sci. Technol. A 28, 347-353 (2010).

${ }^{29}$ J. E. Daalder, J. Phys. D: Appl. Phys. 9, 2379 (1976).

${ }^{30}$ S. Anders, A. Anders, Y. Kin Man, X. Y. Yao, and I. G. Brown, IEEE Trans. Plasma Sci. 21, 440-446 (1993).

${ }^{31}$ ASM Alloy Phase Diagram Database, edited by P. Villars (ASM International, 2002).

${ }^{32}$ A. Anders, Phys. Rev. E 55, 969 (1997).

${ }^{33}$ A. Anders, Appl. Phys. Lett. 85, 6137-6139 (2004).

${ }^{34}$ A. Anders, E. M. Oks, and G. Y. Yushkov, J. Appl. Phys. 102, 043303 (2007).

${ }^{35}$ G. Lins, IEEE Trans. Plasma Sci. 15, 552-556 (1987).

${ }^{36}$ J. Prock, J. Phys. D: Appl. Phys. 19, 1917 (1986).

${ }^{37}$ R. E. Honig and D. A. Kramer, RCA Rev. 30, 285 (1969).

${ }^{38}$ A. Anders, Plasma Sources Sci. Technol. 21, 035014 (2012).

${ }^{39}$ M. Körling and J. Häglund, Phys. Rev. B 45, 13293-13297 (1992).

${ }^{40}$ G. I. Csonka, J. P. Perdew, A. Ruzsinszky, P. H. T. Philipsen, S. Lebègue, J. Paier, O. A. Vydrov, and J. G. Ángyán, Phys. Rev. B 79, 155107 (2009).

${ }^{41}$ M. Fuchs, M. Bockstedte, E. Pehlke, and M. Scheffler, Phys. Rev. B 57, 2134-2145 (1998).

${ }^{42}$ A. T. Paxton, M. Methfessel, and H. M. Polatoglou, Phys. Rev. B 41, 8127-8138 (1990).

${ }^{43}$ C. Kittel, Introduction to Solid State Physics (John Wiley \& Sons, 2004). 